\title{
ELECCIONES EN TIEMPO DE PANDEMIA EN EL URUGUAY: ENTRE LA REALIDAD Y LA LETRA DE LA CONSTITUCIÓN
}

\section{ELECTIONS IN TIMES OF PANDEMIC IN URUGUAY: BETWEEN REALITIY AND THE CONSTITUION'S WORDING}

\section{ELEIÇÕES EM TEMPO DE PANDEMIA NO URUGUAI: ENTRE A REALIDADE E A LETRA DA CONSTITUIÇÃO}

RESUMEN. En el presente artículo el autor se propone analizar cómo incidió la pandemia mundial de COVID-19 surgida a principios de 2020, en la celebración de las elecciones departamentales y municipales previstas constitucionalmente para mayo. La suspensión de las elecciones y su prórroga mediante una solución legislativa, que contó con el consenso de todos los partidos políticos con representación parlamentaria. Esa solución legislativa, a todas luces, inconstitucional, constituye un antecedente de modificación de la Constitución de forma consensuada y consciente por todos los actores políticos del Uruguay, que debe ser analizado a la luz del Estado constitucional de Derecho y del Derecho Electoral.

PALABRAS CLAVES. Elecciones departamentales. Pandemia. Corte Electoral. Partidos Políticos. Inconstitucionalidad.

ABSTRACT. Throughout this paper the author intends to review the impact of the COVID-19 global pandemic emerged in early 2020 on the local and municipal governments elections constitutionally provided for to be held in May. The suspension of such elections and extension thereof by means of a legislative solution was endorsed by all political parties with parliamentary representation. This legislative solution, strikingly unconstitutional, portrays a precedent of an agreed and conscious Constitutional amendment by all political stakeholders in Uruguay that must be analyzed in the light of the constitutional Rule of Law and Electoral Law.

KEY WORDS. Local Governments. Elections. Pandemic. Electoral Court. Political Parties. Unconstitutionality.

\footnotetext{
* Asistente de Derecho Constitucional (Grado 2), Facultad de Derecho, UDELAR. Ayudante del Instituto de Derecho Constitucional, Facultad de Derecho, UDELAR (2017-2021). Docente de Derecho Constitucional, de Derecho Público III, de Jurisprudencia Constitucional y de Taller de Análisis Crítico I. Procurador. Correo electrónico: jampiuru@gmail.com
} 
RESUMO. No presente artigo o autor propõe-se analizar como incidiu a pandemia mundial do COVID-19 surgida no começo do ano 2020, na celebração das eleições departamentais e municipais previstas no texto constitucional para o mês de maio. A suspensão das eleições e sua prorrogação através de uma solução legislativa, que contou com o consenso de todos os partidos políticos com representação parlamentar. Essa solução legislativa, claramente, inconstitucional, constitui um antecedente de modificação da Constituição de maneira consensuada e consciente por todos os atores políticos do Uruguai, o que deve ser analisado à luz do Estado constitucional de Direito e do Direito Eleitoral.

PALAVRAS-CHAVES. Eleições departamentais. Pandemia. Corte Eleitoral. Partidos Políticos. Inconstitucionalidade.

\section{I.- LAS ELECCIONES DEPARTAMENTALES Y MUNICIPALES.}

En el Uruguay, la Constitución uruguaya prevé el calendario electoral: las elecciones internas de los partidos políticos, las elecciones nacionales, la eventual segunda vuelta o balotaje y las elecciones departamentales.

Las elecciones internas de los partidos políticos, son reguladas por ley sancionada por dos tercios del total de componentes de cada Cámara, conforme lo dispuesto en el ordinal $12^{\circ}$ del artículo 77 y mientras, dicha ley no se apruebe, por la disposición transitoria y especial W.

Las elecciones nacionales se celebran el último domingo del mes de octubre, y están establecidas en el ordinal $9^{\circ}$ del artículo 77, y allí se eligen los miembros de las Cámaras del Poder Legislativo, del Presidente y Vicepresidente de la República, así como los miembros de las Juntas Electorales. La segunda vuelta o balotaje entre las dos candidaturas a la Presidencia de la República más votadas que no la mayoría requerida, se efectuarán el último domingo del mes de noviembre siguiente, conforme el artículo 151 de la Constitución.

Las elecciones departamentales se realizan el segundo domingo del mes de mayo del año siguiente a las elecciones nacionales, tal cual surge del inciso tercero del numeral $9^{\circ} \mathrm{del}$ artículo 77 citado. Asimismo, esta norma prevé que también se elijan en esa fecha las autoridades locales electivas. El Legislador ha creado los Municipios y se ha establecido que en la fecha de las elecciones departamentales tendrán lugar las elecciones municipales. 
El 13 de marzo del año 2020 el Poder Ejecutivo, a raíz de la pandemia declarada por la Organización Mundial de la Salud, con fecha 11 de marzo, y habiéndose detectado en territorio nacional uruguayo, la presencia del virus COVID-19 (Coronavirus), dicta el Decreto 93/2020, a los efectos de cumplir la sugerencia de la Organización Mundial de la Salud que recomienda a los países: "mantener una vigilancia firme para encontrar, aislar, someter a pruebas y tratar todos los casos con el fin de cortar las cadenas de transmisión". Por tal motivo, y conforme a lo dispuesto por los numerales $1^{\circ}$ y $2^{\circ}$ de la Ley $\mathrm{N}^{\circ} 9.202$ de 12 de enero de 1934, el Poder Ejecutivo declaró "el estado de emergencia nacional sanitaria como consecuencia de la pandemia originada por el virus COVID-19”. Asimismo dispuso que las "autoridades nacionales, departamentales y municipales competentes deberán evaluar suspender aquellos eventos que impliquen la aglomeración de personas, dado que constituye un factor de riesgo para el contagio de la enfermedad" y asimismo estableció que se "deberán extremar las medidas de limpieza y desinfección en todos los espacios de los establecimientos públicos y privados, en especial los de educación, lugares destinados al trabajo y/o atención al público, cumpliéndose con las recomendaciones dispuestas por el Ministerio de Salud Pública".

La Corte Electoral con fecha 16 de marzo emite una comunicación a los Partidos Políticos del Uruguay y a la Asamblea General del Poder Legislativo, como resultado del análisis de las medidas adoptadas por el Poder Ejecutivo en el marco de la pandemia. En dicha declaración estableció que atento a las medidas adoptadas y previstas, no era posible cumplir con el cronograma de tareas aprobado, tareas entre las que se encuentra: la capacitación de los funcionarios públicos, el armado de los insumos para el día de la elección (urnas, maletas electorales), tampoco podrían cumplir los proveedores de materiales de la Corte Electoral, y sin lugar a dudas, el traslado de más de cuarenta y dos mil personas entre funcionarios públicos, escribanos y custodias de urnas el día de la elección. Señaló, asimismo, la dificultad que tendrían los partidos políticos para trasladar delegados y realizar el correcto contralor de la instancia electoral, atento a las prohibiciones de concentración de personas y aglomeraciones en la vía pública y lugares cerrados. Concluye la Corte Electoral que dadas las circunstancias "con la información disponible al día de la fecha, la Corte Electoral no puede asegurar el normal desarrollo del proceso y de la jornada electoral del 10 de mayo de 2020".

Los partidos políticos, procedieron a conformar una comisión inter-partidaria a los efectos de analizar y buscar soluciones ante la imposibilidad de la Corte Electoral de realizar las elecciones departamentales y municipales previstas para el 10 de mayo de 2020. Conocido este planteo, se suscitó un amplio cúmulo de opiniones por parte de constitucionalistas, académicos y docentes, acerca de la situación planteada, y sus posibles soluciones, las que intentaremos recoger y sintetizar. 
CORREA FREITAS sostuvo que la solución sería una ley constitucional, que reformara la Constitución y fijara una nueva fecha para la elección. Sostuvo que "las leyes constitucionales se plebiscitan en la fecha que se determine. Ese plebiscito se haría el mismo día de la elección departamental, por ejemplo el segundo domingo de setiembre o de octubre" (CABRERA, 2020). En el mismo sentido se expresó ESTEVA GALICCHIO (2020), quien señaló que "la única solución posible indiscutible sería resolver los puntos referidos mediante reforma constitucional. En este sentido, el artículo 331 de la Constitución preceptúa los únicos procedimientos para su reforma”. Expresó que el único mecanismo posible es el consagrado en el Literal D, la llamada Ley Constitucional, cuya dificultad sería la realización del plebiscito "pero no es menester obtener la adhesión de un porcentaje mínimo del total de ciudadanos habilitados".

Por su parte, RISSO señaló que existe una contradicción entre los artículos 77 y 44 de la Constitución, por un lado el deber de votar y por otro el deber de cuidar de la salud de los habitantes: "La cuestión es que hoy, en medio de una pandemia, nos encontramos con que es imposible cumplir con ambos deberes; o se cumple con una disposición o con la otra. Existe una incertidumbre interpretativa que consiste, justamente en no saber a ciencia cierta cuál de os deberes es el que debe primar en este caso. Incertidumbre que debe ser superada mediante una ley con el propósito de elucidar el problema (artículo 85 inciso 20)". (RISSO, 2020).

Señalando la incidencia de los mismos artículos que RISSO, se expresó SAPOLINSKI quien concluyó que "el reconocimiento por el legislador de una situación de crisis imprevisible, sin antecedentes inmediatos, con el único propósito del amparo de la salud de nuestra población, que postergue en forma mínima el acto electoral, habilitando a que la Corte Electoral actúe en condiciones normales y evitando el riesgo de que alguien se contagie durante la espera, o la capacitación, o que evite, alternativamente, una abstención generalizada, no contradice la esencia de nuestro sistema democrático. Más bien, lo contrario". (SAPOLINSKI, 2020).

Contrario a la ley interpretativa se manifestó OCHS, al decir que: "la intervención de los poderes pro mayoría, por medio de una ley interpretativa es doblemente errada. Primero, porque aquí no existe el supuesto objetivo de la procedencia de una ley interpretativa, cual es la duda o incertidumbre engendrada por la norma interpretada. Segundo, porque declarar configurada la situación de objetivo e imposible cumplimiento sobrevenido el acto electoral es competencia exclusiva de la Corte Electoral (art. 322 lit. A de la Constitución)". (OCHS, 2020).

Analizando las dos opciones posibles para resolver el problema interpretativo que se genera con la aplicación la letra de la Constitución, BARDAZANO sintetizó que le resultaba asombroso que la coincidencia de las elecciones en el "tiempo con una pandemia se reciba como un problema irresoluble para la dogmática constitucional, y no como un 
asunto práctico que reclama una solución institucional sensata y acordada". (BARDAZANO, 2020). Plantea y agrega "que: a) si la Asamblea General (por el artículo 85 numeral 20) puede interpretar la Constitución y; b) el artículo 7 habilita a que, por razones de interés general, por ley, es posible restringir el goce de algunos derechos; c) interpretemos que cuando el artículo 7 refiere a la libertad, su alcance incluye la libertad política, que a su vez incluye el sufragio activo y el sufragio pasivo; d) que se trata de proteger especialmente en esta ocasión otros derechos, colectivos e individuales (la seguridad sanitaria, la salud pública, la vida), que se verían afectados en caso de que las elecciones se realizaran el día que la letra de la disposición constitucional indica; e) aun si el consenso no estuviere, dos tercios del total de componentes de cada cámara por tratarse de materia electoral (artículo 77 de la Constitución), alcanzarían; y, f) el principio de continuidad, al que debería hacer referencia expresa la ley que se apruebe, permitiría que sigan las autoridades actuales hasta que asuman las electas en la fecha que la ley disponga". (BARDAZANO, 2020).

El 22 de marzo se reúne la vicepresidenta de la República con representantes de todos los partidos políticos y resuelven buscar los mecanismos necesarios para postergar las elecciones departamentales y municipales en virtud de las medidas adoptadas por la pandemia (La Diaria, 23 de marzo de 2020). Se plantearon dos opciones: reforma constitucional o norma legislativa.

Respecto de la reforma constitucional, la Corte Electoral señaló que era imposible realizar un plebiscito porque implicaba las mismas actividades que realizar las elecciones, y cada vez que transcurre el tiempo, más se agrava la situación y las condiciones empeoran (La diaria, 24 de marzo de 2020).

Ante esta realidad, los partidos políticos acordaron la presentación de un proyecto de ley en el cual se posterguen las elecciones departamentales y municipales, con los fundamentos acordados por el sistema político.

\section{III.- LA SOLUCIÓN CREADA: LEY N 19.875.}

El proyecto de Ley ingresó al Senado de la República con la firma de los senadores Charles Carrera, Guillermo Domenech, Raúl Lozano, Gustavo Penadés y Adrián Peña.

III.1.- Exposición de motivos.

En la exposición de motivos del proyecto de ley, los legisladores reconocen que la situación en el país ante la declaratoria de emergencia nacional sanitaria producto de la pandemia mundial, afecta el normal desarrollo de las elecciones departamentales y municipales previstas para el 10 de mayo de 2020, citando las disposiciones constitucionales 
que establece la fecha.

Por tal motivo señalan que ante esta situación "pone en juego cuatro disposiciones constitucionales, que a su vez implican derechos fundamentales que deben comulgar entre sí". Primero, el artículo $7^{\circ}$ de la Constitución dispone que los habitantes de la República tienen derecho, en clave de garantía, a ser protegidos en el goce de todos sus derechos. La protección le cabe activamente al Estado.

Segundo, el artículo 77 numeral $9^{\circ}$ de la Constitución y el derecho "fundamental comprometido es el derecho del ciudadano a ser elector y elegible en las elecciones departamentales y municipales, es decir, el derecho a la certeza de la celebración de elecciones libres, en las que los ciudadanos puedan ser electores y elegibles". Asimismo señalan que "dentro de las condiciones que establece el artículo 77, el parámetro de fijación de la fecha de las elecciones libres a nivel departamental y municipal".

En tercer lugar, el numeral $7^{\circ}$ del artículo 77, y el derecho fundamental comprometido consiste "en el derecho del elector a sufragar en elecciones departamentales y municipales a celebrarse en fecha cierta, lo cual es también un deber del elector. Dada la trascendencia del acto del sufragio, esta disposición constitucional confía en el legislador las garantías del sufragio y de la elección, exigiéndole su aseguramiento por una ley con máximo consenso político posible, traducido en la mayoría calificada requerida".

Y por último citan el artículo 44 de la Constitución, que establece que el Estado legislará en todas las cuestiones relacionadas con la salud e higiene pública, y que todos los ciudadanos tienen el deber de cuidar su salud, lo que constituye además "en sí, de un derecho fundamental, es decir, una situación jurídica compleja de derecho-deber". En aplicación de este artículo el Poder Ejecutivo dictó el Decreto 93/2020 ya analizado.

Atento a esto concluyen que la celebración de las elecciones departamentales y municipales previstas afectaría el contenido de los derechos fundamentales consagrados en las normas desarrolladas.

Entienden los firmantes que "la prórroga de la fecha de previsión constitucional, a otra fecha cierta, no implica una afectación legislativa al contenido esencial del derecho a elecciones departamentales y municipales libres, en fecha cierta, sino por el contrario, constituye una garantía para la celebración de dichas elecciones con carácter libre y universal y a la vez, respeta el contenido esencial del derecho-deber de la salud".

Agregan que corresponde "cometer a la Corte Electoral a que, en un plazo razonable, fije fecha para las elecciones departamentales considerando las circunstancias, y atento a su competencia originaria en materia de elecciones, de acuerdo con lo dispuesto por el artículo 322 literal A de la Constitución de la y análogamente a la competencia prevista por el artículo 327 de la Constitución".

Respecto del mandato de las actuales autoridades departamentales y municipales señalan que conforme lo dispuesto en los artículos 262, 268 inciso final, 287 y artículos 9 a 12 de 
la Ley $\mathrm{N}^{\circ} 19.272$ de 18 de septiembre de 2014, concluyen que el proyecto de ley asegura la continuidad jurídico-funcional y política de los órganos electivos de los Gobiernos Departamentales y de los Municipios.

III.2.- Texto del articulado.

El proyecto ingresó a la Cámara de Senadores y fue aprobado en la sesión del $1^{\circ}$ de abril de 2020 y pasó a la Cámara de Representantes donde se aprobó el 2 de abril, siendo promulgada por el Poder Ejecutivo con el $N^{\circ} 19.875$ el 8 de abril de 2020 y publicada en el Diario Oficial el 16 de abril de 2020.

El artículo primero declara que ante la pandemia mundial del virus COVID-19, que motivó el estado de emergencia sanitaria nacional decretado por el Poder Ejecutivo y la implementación inmediata de medidas tendientes a preservar la salud de los habitantes, no están dadas las garantías para la celebración de las elecciones departamentales y municipales previstas para el 10 de mayo de 2020, en tanto se afectarían derechos fundamentales establecidos en las Secciones II y III de la Constitución de la República, y las leyes electorales vigentes.

Por el artículo segundo faculta a la Corte Electoral a prorrogar, por única vez, la fecha de la celebración de las elecciones departamentales y municipales previstas en el artículo 77 numeral $9^{\circ}$ de la Constitución, no más allá del domingo 4 de octubre de 2020. La fecha de la prorroga la debe resolver en un plazo de quince días por la mayoría prevista en el artículo 327 de la Constitución uruguaya, señalando que el padrón electoral será el previsto para las elecciones postergadas.

El artículo tercero, prorroga las funciones de las autoridades departamentales y municipales actuales, hasta la fecha que asuman las autoridades proclamadas por las Juntas Electorales respectivas. Por el artículo cuarto señalan que el período de actuación de las nuevas autoridades culminará cuando asuman las autoridades electas en el próximo período electoral, conforme lo dispuesto por la Constitución.

\section{IV.- LA REGLAMENTACIÓN POR LA CORTE ELECTORAL.}

La Corte Electoral en el ejercicio de lo dispuesto por el artículo $2^{\circ}$ de la Ley $\mathrm{N}^{\circ} 19.875$ dictó la reglamentación comunicada, por Circular $\mathrm{N}^{\circ} 10.853$ de 17 de abril de 2020, estableciendo que la misma por las mayorías previstas en el artículo 327 de la Constitución, es decir, aprobarse por el voto conforme de dos tercios de miembros de la Corte, de los cuales al menos tres los miembros designados por dos tercios de la Asamblea General. Atento a esto, señaló que las reglas de derecho a regular conductas humanas, y que dicha normativa debe guardar la debida tensión con la realidad; que todos los preceptos cons- 
titucionales deben ser interpretados armónicamente; que las competencias del organismo están establecidas en el artículo 322 de la Constitución, además de las que establezca la ley; que el literal A del mencionado artículo 322 le atribuye la competencia de conocer en todos los actos y procedimientos electorales; y que en ese marco, ella ejerce competencia excluyente y exclusiva en materia electoral.

Por tanto, resolvió prorrogar para el 27 de septiembre de 2020, las elecciones departamentales y municipales previstas en el numeral 9 del artículo 77 de la Constitución de la República. El padrón de habilitados para votar es el mismo que fuera aprobado el 21 de marzo, y comunicado a los partidos políticos el 26 de marzo, para las elecciones del 20 de mayo. Además, estableció que los candidatos a la Intendencia, titulares y suplentes, serían los ya nominados por los Órganos Deliberativos Departamentales de los Partidos Políticos .

\section{V.- ANÁLISIS DE LA SOLUCIÓN CREADA POR EL LEGISLADOR.}

Estamos ante una Ley que es contraria a la Constitución uruguaya por razón de contenido, atento a lo dispuesto en el ordinal $9^{\circ}$ del artículo 77, lo cual a todas luces es claro. La fecha de las elecciones departamentales se encuentra regulada por la Constitución conforme lo expresado.

Ahora bien, corresponde señalar que el Legislador ha optado por una solución que, si bien entendemos es el resultado de un pacto de los partidos políticos que intervienen en la vida electoral del país, no podemos compartir.

En primer lugar, la Corte Electoral reconoce que no posee competencia para cambiar la fecha de las elecciones, y ante una realidad comprobada y contrastable, deja en manos del sistema político la solución. Porque la respuesta es clara: solo reformando la Constitución es posible cambiar las elecciones.

En segundo lugar, la Corte Electoral está obligada por las disposiciones constitucionales y legales a no dejar de resolver los asuntos objeto de su competencia, aun cuando no exista reglamentación pertinente. Así lo hizo respecto de la reglamentación del recurso de referéndum, que en 1986 no existía ley reglamentaria, y la Corte procedió a suplir la reglamentación legal.

En tercer lugar, es claro que estamos ante un dilema en donde hay contradicción entre la realidad y la norma constitucional. La realidad aparece afectada por una pandemia de escala sin precedente, con una emergencia sanitaria decretada por el Poder Ejecutivo al amparo de la normativa en materia de salud pública. Por otra parte, la norma constitucional fija la realización de las elecciones departamentales, en donde se encuentra afectado el derecho a ser elector y elegible y la obligación de votar consagradas constitucionalmente. El derecho de la salud versus los derechos políticos, han señalado algunos constituciona- 
listas.

En la doctrina argentina SAGÜES señala que una fuente de la desconstitucionalización surge de la "reiterada sanción de leyes o decretos inconstitucionales, pero no declarados así por los órganos de control de constitucionalidad, con lo que, indirectamente, rigen por encima de la constitución y de hecho bloquean o anestesian las reglas constitucionales que los contradicen". (SAGÜES, 2007: 192-193). Tal como ha dicho BARDAZANO (2020), en nuestro país existen claras violaciones de la Constitución uruguaya que han sido toleradas por la Suprema Corte de Justicia respecto, por ejemplo, del artículo 216 de la Carta. Incluso se ha puesto en duda la rigidez de la Constitución uruguaya, en un estudio dirigido por SARLO, (BURSTIN et ALL; 2009).

Sin dudas que el derecho a la salud se ha visto afectado y este irradia y afecta a los derechos políticos y a la organización misma de las elecciones previstas, ya que impide a los partidos políticos la correcta participación en el proceso electoral. La Corte Electoral no puede organizarlas de forma tal que aseguren, el cumplimiento de las garantías necesarias para las elecciones.

En cuarto lugar, el legislador ha aplicado un criterio analógico a los efectos de la fijación de la fecha por parte de la Corte Electoral, al requerirse que sea mediante las mayorías establecidas constitucionalmente para anular las elecciones, es decir, dos tercios del total de componentes, debiendo contar con el voto conforme de al menos, tres miembros de los elegidos por dos tercios de la Asamblea General. Esta disposición busca otorgar mayor legitimidad a la prórroga dispuesta por la Ley $\mathrm{N}^{\circ} 19.875$, atento a la composición del máximo órgano electoral. La decisión fue tomada por la unanimidad de los miembros de la Corte Electoral.

Asimismo, se ha establecido que, en lo que respecta a las autoridades que actualmente se encuentran ejerciendo sus cargos, se prorroga a su vez, y por única vez el mandato, por lo que el período de las autoridades que sean electas el 27 de septiembre se acortará hasta julio de 2025. Entendemos que, en aplicación del principio de continuidad jurídica, se impone esta solución, para evitar la acefalía de los cargos en pugna.

En quinto lugar, entendemos que la Ley es inconstitucional, pero creemos que atento a la forma y el proceso por el cual se sancionó la Ley de marras, es muy difícil que pueda considerarse la posibilidad de que exista un legitimado para solicitar por vía de acción la declaración de inconstitucionalidad ante la Suprema Corte de Justicia. En efecto, la Corte Electoral y los partidos políticos que han intervenido en las negociaciones y sanción de la Ley la han aplicado, la han tolerado y la han reglamentado sin poner en duda la inconstitucionalidad. Sin embargo, entendemos que los candidatos a los cargos electivos cuya inscripción se encuentra registrada ante el máximo órgano de la Justicia Electoral: los candidatos a las Intendencias Departamentales, podrían sí accionar ante la Suprema Corte de Justicia puesto que el cambio de las fechas les puede afectar, en cuanto a su legítimo 
interés de que las elecciones se realizarán en la fecha prevista constitucionalmente.

\section{VI.- CONCLUSIONES.}

La pandemia declarada por la Organización Mundial de la Salud, y conocida como COVID-19, y su ingreso al Uruguay, provocó que el Poder Ejecutivo decrete la emergencia sanitaria nacional, provocando la afectación de las organizaciones de las elecciones departamentales y municipales previstas para el segundo domingo de mayo de 2020.

El sistema político acordó la sanción de la Ley $\mathrm{N}^{\circ} 19.875$, a iniciativa de los partidos políticos con representación en el Senado de la República, que fue aprobada por la unanimidad del Senado de la República y por un solo voto negativo en la Cámara de Representantes. En ambos casos se obtuvieron los dos tercios del total de componentes en cada Cámara.

La solución contenida en la normativa que hemos analizado, es inconstitucional por razones de forma y de contenido, pero entendemos que, excepto los candidatos a las Intendencias Departamentales, quienes podrían solicitar la inconstitucionalidad de la misma, han tolerado y participado en la sanción de la ley.

Entendemos que en un Estado constitucional de Derecho son necesarias las mayores garantías para el desarrollo de las elecciones, de forma tal de asegurar a todos los partidos políticos, candidatos y electores que no existan impedimentos para el normal desarrollo de los comicios. La declaración de emergencia sanitaria como resultado de una pandemia, impide por razones de salud, que la población pueda desplazarse libremente, así como a los partidos políticos no les permite el control a través de sus delegados, y los candidatos hacer campaña electoral. Todos estos elementos hacen que la democracia se vea afectada duda, y que la soberanía que debe ejercer la Nación a través del Cuerpo Electoral se vea afectada, ejercer libremente.

Hubiera sido factible una Ley que por esta vez, dejara sin efectos las sanciones por el no ejercicio del voto consagrado constitucionalmente, pero podría objetarse la escasa participación electoral, no sólo de los electores sino de los partidos políticos, actores necesario del sistema.

En tiempos de crisis, es necesario contar con mecanismos que permitan la salvaguarda de las personas y de las Instituciones pero también la plena vigencia de la Constitución de la República, procurando que la solución no sea la violación tolerada de la misma. Como señala BLENGIO "que esta experiencia nos sirva para asumir como imperativo en un futuro inmediato, la tarea de adecuar los ordenamientos jurídicos y las Constituciones, a una realidad vertiginosa que permita elaborar salidas coyunturales flexibilizando fórmulas herméticas". (BLENGIO, 2020). 


\section{BIBLIOGRAFÍA CONSULTADA.}

BARDAZANO, G. (21 de marzo de 2020). La Constitución y la pandemia. La diaria. Recuperado de https://ladiaria.com.uy/articulo/2020/3/la-constitucion-y-la-pandemia/

BLENGIO, M. (2020). Elecciones departamentales y municipales en tiempos de COVID - 19. Revista de Derecho Público. Recuperado de http://www.revistaderechopublico. com.uy/ojs/index.php/Rdp/announcement/view/7

BURSTIN, D. et ALL. (2009). La Constitución uruguaya ¿Rígida o flexible? Un estudio de teoría constitucional contemporáneo aplicado al caso uruguayo. Montevideo: Facultad de Derecho, Universidad de la República.

ESTEVA GALICCHIO, E. (2020). Coronavirus y elecciones departamentales y municipales (Uruguay 2020). Comunicado $\mathrm{N}^{\circ}$ 6. Montevideo: Centro de Documentación y Estudios Constitucionales del Uruguay.

OCHS, D. (19 de marzo de 2020). Las elecciones municipales I. Semanario Búsqueda. 2064. Recuperado de https://www.busqueda.com.uy/nota/las-elecciones-municipales-i/ 1s-116939-5d3f1937080305e42166 Fecha de consulta: 5 de mayo de 2020.

RISSO FERRAND, M. (26 de marzo de 2020). Elecciones departamentales I. Semanario Búsqueda. 2065. Recuperado de https:/www.busqueda.com.uy/nota/elecciones-departamentales-i/ls-116939-881ae93c224f36aad38b Fecha de consulta: 5 de mayo de 2020.

SAGÜES, N. (2007). El concepto de desconstitucionalización. Revista de Derecho. 2, 181-195.

SAPOLINSKI, J. (2 de abril de 2020). (19 de marzo de 2020). Las elecciones municipales II. Semanario Búsqueda. 2064. Recuperado de https://www.busqueda.com.uy/nota/ las-elecciones-municipales-ii/ls-116939-67543cb0feea228368aa Fecha de consulta: 5 de mayo de 2020.

Artículos en diarios.

Corte Electoral sugirió no plebiscitar el cambio de fecha de las elecciones departamentales. (24 de marzo de 2020). La diaria. Recuperado de https://adiaria.com.uy/articulo/2020/3/ corte-electoral-sugirio-no-plebiscitar-el-cambio-de-fecha-de-las-elecciones-departamen- 
tales/ Fecha de consulta: 5 de mayo de 2020.

Elecciones departamentales: Partidos políticos se reúnen este martes con la Corte Electoral para analizar posibilidades. (23 de marzo de 2020). La diaria. Recuperado de https:// ladiaria.com.uy/articulo/2020/3/elecciones-departamentales-partidos-politicos-se-reunen-este-martes-con-la-corte-electoral-para-analizar-posibilidades/ Fecha de consulta: 5 de mayo de 2020.

Risso versus Correa Freitas: las dos "bibliotecas" que dividen a los partidos políticos para postergar las elecciones departamentales. (21 de marzo de 2020). La diaria. Recuperado de

https://ladiaria.com.uy/articulo/2020/3/risso-versus-correa-freitas-las-dos-bibliotecas-que-dividen-a-los-partidos-politicos-para-postergar-las-elecciones-departamentales/ Fecha de consulta: 5 de mayo de 2020.

CABRERA, S. (18 de marzo de 2020). Expertos y políticos chocan sobre cómo atrasar las elecciones departamentales. El País. Recuperado de https://www.elpais.com.uy/informacion/politica/expertos-politicos-chocan-atrasar-elecciones-departamentales.html Fecha de consulta: 5 de mayo de 2020 .

Referencias normativas.

Uruguay. Ley $\mathrm{N}^{\circ}$ 19.875. Prórroga de fecha para la celebración de las elecciones departamentales y municipales. Diario Oficial. 20 de abril de 2020.

Uruguay. Ley N 9.202. Ley Orgánica de Salud Pública. Diario Oficial. 22 de enero de 1934.

Fecha de recepción: 10 de mayo 2020.

Fecha de aceptación: 12 junio 2020. 